\title{
SURGICALLY INDUCED DIFFUSE SCLERITIS FOLLOWING CATARACT SURGERY
}

\author{
J. A. SCOTT and L. G. CLEARKIN \\ Barnsley
}

\begin{abstract}
SUMMARY
We report 21 cases, representing $3.1 \%$ of a total of 682 cataract patients, of surgically induced diffuse scleritis (SIDS) following planned extracapsular cataract extraction with intraocular lens insertion. The mean age was significantly lower in the patients with SIDS (mean 62.5 years; SD 13.68) when compared with the non-scleritic group (mean 73.6 years; SD 10.2; Mann-Whitney $U$-test, $p=0.0003$ ). There was an association of SIDS with general anaesthetic (chi-squared test, $p=\mathbf{0 . 0 0 0 8}$ ). Twenty of 21 patients responded to oral non-steroidal anti-inflammatory agents with good visual result.

Surgically induced necrotising scleritis (SINS) is recognised as a rare complication of ophthalmic surgery. It is reported following cataract surgery, ${ }^{1-10}$ penetrating keratoplasty, ${ }_{1}$ strabismus surgery for thyroid ophthalmopathy ${ }^{12}$ and cataract surgery complicated by infection. ${ }^{13}$ Surgically induced diffuse scleritis (SIDS) is less well recognised. Ansons et al. ${ }^{14}$ reported 3 cases following extracapsular cataract extraction, complicated by vitreous prolapse when anterior chamber intraocular lenses were implanted. We report 21 cases, representing $3.1 \%$ of cataracts performed by a single surgical firm, of SIDS following extracapsular cataract extraction with intraocular lens insertion in patients who, apart from 1 patient who suffered from rheumatoid disease, had no predisposition to, nor previous evidence of, scleritis.
\end{abstract}

\section{METHODS}

\section{Patients}

Patients were identified from a database (dBase IV) held on a desktop personal computer. Data regarding pre-operative systemic and/or ocular disease, together with intraand post-operative complications affecting patients undergoing cataract surgery with intraocular lens implantation,

From: Department of Ophthalmology, Barnsley District Gencral Hospital, Barnsley, South Yorkshire, UK.

Correspondence to: Mr J. A. Scott, FRCS(Glasg), MRCOphth, St Paul's Eye Department, 8Z Link, Royal Liverpool University Hospital. Prescot Street, Liverpool L7 8XP, UK. were recorded. Details were entered by one of us (L.G.C.) at a minimum of 6 months following surgery. Case notes of those patients who had developed scleritis were subsequently examined in more detail. Visual outcome, symptomatology, clinical signs and treatments were recorded. B-scan ultrasonography, if performed, was also reviewed.

\section{Surgical Procedures}

Pre-operative mydriasis was achieved by instillation of $\mathrm{g}$. phenylephrine $10 \%$ and g. cyclopentolate $1 \%$. In cases with a history of previous ocular surgery or diabetes, $g$. atropine $1 \%$ was instilled in addition. Surgery was done under either general anaesthesia or local peribulbar anaesthesia (g. amethocaine topically, peribulbar injection of lignocaine $2 \%$ with adrenaline 1:100 000, bupivicaine $0.5 \%$ and hyaluronidase (Hyalase) 1500 i.u.).

All surgery was performed by a single consultant surgeon (L.G.C.) or under his direct supervision. Extracapsular cataract extraction was achieved in a standard fashion with only minor variations. A superior rectus suture was placed. The incision was almost invariably corneal. Sodium hyaluronate (Healon) was instilled prior to capsulotomy (beercan, capsulorhexis or endocapsular). Following hydrodissection and nucleus expression, the cortical lens matter was aspirated using a two-way irrigation aspiration technique. The posterior chamber lenses, various models, were inserted directly, under sodium hyaluronate (Healon), and dialled if appropriate. In those eyes which had previously undergone surgery posterior synechiae were divided prior to capsulotomy and often a peripheral iridectomy was converted into a sector iridectomy and sutured at the end of the procedure; frequently a single inferior sphincterotomy was also performed. Anterior vitrectomy, mechanical or automated, was performed following loss of posterior capsular integrity. The wound was sutured using 10.0 nylon as a continuous suture, with the anterior chamber maintained with air, if necessary; the anterior chamber was re-formed using balanced saline solution. Post-operatively, patients received g. betnesol-N 
q.d.s. and either g. cyclopentolate $1 \%$ or g. atropine $1 \%$ b.d.

\section{Diagnosis and Treatment}

All patients underwent detailed examination including slit lamp biomicroscopy, and fundal examination with +90 dioptre lens and/or indirect ophthalmoscope. Although a number of different observers saw the patients, one of us (L.G.C.) had observed all the patients. Scleritis was diagnosed clinically ${ }^{15.16}$ on the basis of a painful red eye with associated photophobia and blurred vision. The pain was usually sufficiently severe to prevent, or wake the patient from, sleep. Clinical signs included a red eye with violaceous hue, ptosis, and no elevation of intraocular pressure. The scleral and episcleral inflammation was found to be adjacent to the operative wound (Fig. 1). Uveitis was never more than would have been anticipated post-operatively. Vascular shutdown or scleral necrosis was never recognised clinically. B-scan ultrasonography was performed on 3 cases and confirmed scleral thickening relative to the fellow eye at diagnosis which reversed following treatment and resolution of inflammation.

In addition to routine post-operative topical steroid and mydriatic, 20 of 21 cases of scleritis were treated with an oral non-steroidal anti-inflammatory agent (ibuprofen $400 \mathrm{mg}$ t.d.s. minimum ( 18 cases); naproxen $250 \mathrm{mg}$ b.d. ( 2 cases). The dose of topical steroid was increased in 12 cases.

Data were analysed using Arcus statistical software.

\section{RESULTS}

Of a total of 682 patients (mean age 73.6 years, SD 10.2) who had cataract operations, with a minimum of 6 months follow-up, 26 developed diffuse scleritis post-operatively. Records of 21 patients (mean age 62.5 years, SD 13.68) with diffuse scleritis were located and examined. The mean age of the patients who developed scleritis was significantly lower than that of all the patients who underwent cataract surgery (Mann-Whitney $U$-test, $p=0.0003$ ). Of the scleritic patients, 11 were female (mean age 66.5 years; SD 13.61; range 45-83) and 10 male (mean age 58.2 years; SD 13.05; range 38-83).

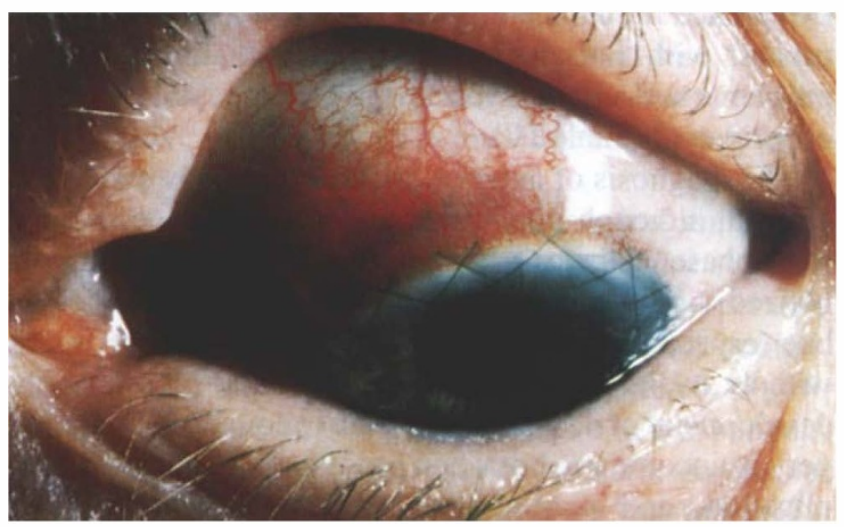

Fig. 1. Photograph of the left eye showing scleral inflammation superiorly in a patient with surgically induced diffuse scleritis occurring on the ninth day following cataract surgery.
There was no significant difference in the mean age between the sexes in the scleritic group (unpaired student's $t$-test, $p>0.1$ ).

The mean age of all the patients who underwent general anaesthesia (mean 68.4 years; SD 13.6; range 27-90) was significantly lower than that of those who underwent local anaesthesia (mean age 74.5 years; SD 9.4; range 51-91; $p<0.0001$, Mann-Whitney $U$-test) overall. There was a similar age difference in mean ages in the patients who developed SIDS after general anaesthesia (mean age 54.1 years; SD 10.3; range 38-69) compared with those who developed SIDS following local anaesthesia (mean age 70.2 years; SD 11.9; range $51-83 ; p=0.004$, Student's $t$-test).

The types of surgery performed on patients who developed SIDS are shown in Table I. Possible pre- and peroperative factors relating to the development of postoperative diffuse scleritis are summarised in Table II.

Twelve left and 9 right eyes were involved. Two patients had suffered previous trauma: 1 had sustained a corneal abrasion, and 1 a hyphaema with subluxation of the lens. Of the two myopic patients, 1 had previously undergone a prophylactic barrage argon laser treatment.

In 18 cases the operated eye had not undergone previous surgery. Surgery had previously been performed in the fellow eye in 6 cases: 3 extracapsular cataract extraction and posterior chamber intraocular lens implant (ECCE + PCIOL), 2 trabeculectomies (TRAB) and 1 peripheral iridectomy (PI). Of the 5 patients who had glaucoma, 3 had undergone previous ipsilateral trabeculectomy and 2 were treated medically with topical timolol and pilocarpine. There was no association between chronic open angle glaucoma and scleritis (chi-squared test, $p=0.062$ ). There was no association between any previous surgery in either eye in the scleritic group (chisquared test, $p=0.48$ ), nor with previous ipsilateral trabeculectomy (chi-squared test, $p=0.28$ ), peripheral iridectomy or iridotomy (chi-squared test, $p=0.53$ ) or per-operative iris surgery (synaechiotomy/synaechiolysis) (chi-squared test, $p=0.41$ ). There was no association with previous contralateral cataract surgery (chi-squared test, $p=0.55$ ).

Local peribulbar anaesthetic was used in 11 patients, whilst general anasesthetic was used for 10 . The majority

Table I. Number of patients developing diffuse scleritis according to type of cataract surgery performed

\begin{tabular}{lc}
\hline $\begin{array}{l}\text { Operation performed } \\
\text { on the affected eye }\end{array}$ & $\begin{array}{l}\text { No. of cases of } \\
\text { diffuse scleritis }\end{array}$ \\
\hline ECCE + PCIOL & 15 \\
ECCE + AV + PCIOL & 2 \\
ECCE & 2 \\
ECCE + AV & 1 \\
ECCE + PCIOL + TRAB & 1 \\
Total & 21 \\
Per-operative iris surgery & 3 \\
\hline
\end{tabular}

ECCE, extracapsular cataract extraction; PCIOL, insertion of posterior chamber intraocular lens: $\mathrm{AV}$, anterior vitrectomy; TRAB, trabeculectomy; Per-operative iris surgery, synaechiotomy/synaechiolysis or sphincterotomy. 
Table II. Incidence of pre- and per-operative factors for scleritic and non-scleritic cataract patients

\begin{tabular}{|c|c|c|c|c|}
\hline & $\begin{array}{c}\text { Incidence in } \\
\text { scleritic patients }\end{array}$ & $\begin{array}{l}\text { Incidence in all } \\
\text { cataract patients }\end{array}$ & $\begin{array}{c}\text { Chi-squared } \\
\text { test }^{\mathrm{a}}\end{array}$ & $\begin{array}{c}\text { NCSS incidence } \\
\text { data }^{\mathrm{b}}\end{array}$ \\
\hline \multicolumn{5}{|l|}{ Laterality } \\
\hline Right & $9 / 21$ & $361 / 682$ & $p=0.47$ & \\
\hline Left & $12 / 21$ & $321 / 682$ & & \\
\hline Diabetes mellitus & $3 / 21$ & $36 / 682(5.3 \%)$ & $p=0.17$ & $\begin{array}{l}\text { Retinopathy: } \\
4.0 \%(3.02-5.13)\end{array}$ \\
\hline Treated chronic open angle glaucoma & $5 / 21$ & $65 / 682(9.5 \%)$ & $p=0.06$ & $10.6 \%(8.92-12.1)$ \\
\hline Previous contralateral cataract surgery & $3 / 21$ & $110 / 682(16.1 \%)$ & $p=1.0$ & $32 \%$ \\
\hline Previous ipsilateral trabeculectomy & $3 / 21$ & $43 / 682 \quad(6.3 \%)$ & $p=0.28$ & \\
\hline Previous ipsilateral peripheral iridectomy & $1 / 21$ & $7 / 682(1.02 \%)$ & $p=0.53$ & \\
\hline Any previous surgery to either eye & $6 / 21$ & $157 / 682(23.4 \%)$ & $p=0.57$ & \\
\hline Per-operative iris surgery & $3 / 21$ & $60 / 682 \quad(8.8 \%)$ & $p=0.41$ & \\
\hline $\begin{array}{l}\text { Per-operative loss of posterior capsular } \\
\text { integrity or vitreous loss }\end{array}$ & $3 / 21$ & $36 / 682 \quad(5.3 \%)$ & $p=0.17$ & \\
\hline \multicolumn{5}{|l|}{ Anaesthetic } \\
\hline Local & $11 / 21$ & $556 / 682(81.5 \%)$ & & $46 \%$ \\
\hline General & $10 / 21$ & $126 / 682(18.5 \%)$ & $p=0.0009$ & $54 \%$ \\
\hline
\end{tabular}

${ }^{a}$ Chi-squared test with Yates' correction for expected values less than $5 ; p$ values are given for comparison of scleritic with non-scleritic cataract patients.

${ }^{6}$ NCSS, National Cataract Surgery Survey. ${ }^{18.19}$

(556) of the 682 patients in this series underwent surgery under local anaesthetic, whilst 126 had surgery performed under general anaesthetic. There was an association of SIDS with general anaesthesia (chi-squared test, $p=0.0009$ ) when compared with local anaesthetic (Table II).

A review of the general medical histories for known risk factors for the development of scleritis revealed only 1 patient: a 79-year-old woman who had a history of rheumatoid disease but no previous history of scleritis. Three of 21 patients were non-insulin-dependent diabetics - an incidence not significantly different from that $(36 / 682)$ in patients who did not develop scleritis (chi-squared test, $p=0.38$ ). Nine patients were smokers, 8 were nonsmokers and in 4 it was unknown. None was known to have any other predisposing collagen disorder or vasculitis, nor history of scleritis. No scleritic patient is known to have died at the time of the review.

The interval to presentation generally was short: 8 of 21 cases had presented by 1 week and 19 of 21 by the first post-operative outpatient appointment at 2 weeks. One case each presented at 3 weeks and 9 weeks. Eighteen cases resolved with treatment within 6 weeks of diagnosis, yielding a best corrected Snellen visual acuity of at least

Table III. Numbers of patients with each level of visual acuity at presentation and after resolution of surgically induced diffuse scleritis

\begin{tabular}{lcc}
\hline $\begin{array}{l}\text { Snellen } \\
\text { visual acuity }\end{array}$ & $\begin{array}{c}\text { No. of patients at } \\
\text { presentation with scleritis }\end{array}$ & $\begin{array}{c}\text { No. of patients at } \\
\text { resolution of scleritis }\end{array}$ \\
\hline $6 / 5$ & 0 & 1 \\
$6 / 6$ & 1 & 4 \\
$6 / 9$ & 1 & 5 \\
$6 / 12$ & 2 & 4 \\
$6 / 18$ & 4 & 4 \\
$6 / 24$ & 3 & 1 \\
$6 / 36$ & 4 & 0 \\
$6 / 60$ & 2 & 1 \\
CF & 4 & 1 \\
& 21 & 21 \\
\hline
\end{tabular}

$\mathrm{CF}$, counting fingers.
6/6 (5 patients), 6/9 (5 patients), 6/12 (4 patients) or 6/18 (4 patients) (Table III); only 1 case runs a protracted course of more than 2 years.

\section{DISCUSSION}

The demographic data of the cataract patients and cataract operations are generally in keeping with the findings of the National Cataract Surgery Survey, ${ }^{18.19}$ except that a greater proportion of our patients had surgery under local anaesthesia (Table II).

We believe that SIDS is a frequently overlooked condition. Cataract surgeons anticipate anterior uveitis as an inevitable consequence of cataract surgery and do not regard this as a complication of surgery. In this series SIDS was the second most common complication within the first 3 months following cataract surgery ( $3.1 \%)$. Only astigmatism requiring suture removal was more common (9.5\%). Persistent uveitis $(2.3 \%)$ and pericapsular fibrosis $(1.9 \%)$ were less frequent, while glaucoma, endophthalmitis, iris prolapse and wound dehiscence, subluxated implant lens and others each occurred in less than $1 \%$ of cases. Contemporaneous data collected for the National Cataract Surgery Survey suggest that $20 \%$ of patients experience complications in the early post-operative period, with rates of uveitis, endophthalmitis, wound problems and vitreous loss that are comparable with our experience $^{19}$ (Table IV).

The diagnosis of anterior diffuse scleritis is essentially clinical, although often not considered in the post-operative phase, and was made on the grounds of a history of blurred vision, a deeply painful red eye with violaceous hue (especially when viewed in daylight), ptosis, usually without uveitis or elevation of intraocular pressure. The development of deep or severe pain following cataract surgery is uncommon, but when present may indicate a complication, and requires explanation. Scleritic pain is characteristically severe and may wake the patient from sleep. Other potential causes of post-operative pain and redness were excluded, i.e. corneal abrasion, infection, 
Table IV. Incidence of post-operative complications requiring intervention in our surgical unit

\begin{tabular}{|c|c|c|c|}
\hline \multirow[b]{2}{*}{ Complication } & \multirow[b]{2}{*}{$\begin{array}{l}\text { Incidence }(\%) \text { in } \\
\text { first } 3 \text { months }\end{array}$} & \multicolumn{2}{|c|}{ NCSS data } \\
\hline & & $\begin{array}{l}\text { Incidence }(\%) \text { at } \\
\text { first outpatient visit }\end{array}$ & $\begin{array}{c}\text { Incidence }(\%) \\
\text { at } 3 \text { months }\end{array}$ \\
\hline Astigmatism requiring suture removal & 9.5 & $?$ & $?$ \\
\hline Diffuse scleritis & 3.1 & NR & NR \\
\hline Persistent uveitis & 2.3 & 2.1 & 1.1 \\
\hline Pericapsular fibrosis & 1.9 & - & 6.3 \\
\hline Iris prolapse and wound dehiscence & $<1$ & 1 & 0.2 \\
\hline Glaucoma or raised IOP & $<1$ & 3.3 & 2.3 \\
\hline Endophthalmitis & $<1$ & 0.2 & - \\
\hline Subluxed IOL & $<1$ & $\cdots$ & 0.3 \\
\hline
\end{tabular}

IOP, intraocular pressure; IOL, intraocular lens; NR, not reported.

"NCSS, National Cataract Surgery Survey" data are given for comparison.

raised intraocular pressure and severe uveitis. Uveitis, in particular, was notable by its absence, but if present it was mild and in keeping with our normal post-operative experience. No patient with SIDS required additional therapeutic intervention for uveitis. Although Watson and Hayreh $^{15}$ described $35 \%$ of anterior diffuse scleritics to have anterior uveitis, and Wilhelmus et $a l .{ }^{17}$ in a combined histological and clinical review, found $45 \%$ of enucleated scleritic eyes and $25 \%$ of clinically examined scleritic eyes to have had anterior uveitis, Sainz-de-la-Maza and Foster ${ }^{6}$ found no uveitis in 10 cases of post-operative necrotising scleritis. Intraocular pressure is usually normal in scleritis, unless there is a ciliochoroidal effusion ${ }^{2()}$ or other secondary reason. ${ }^{21.22}$ No evidence, however, of necrotising disease was seen in any patient either.

Although anterior segment fluorescein angiography is useful in demonstrating scleral vascular shutdown, it is not a useful discriminator in anterior segment inflammation. B-scan ultrasonography is extremely helpful in confirming the diagnosis. This is a simple non-invasive technique which will show thickening of the posterior coats of the affected eye compared with its fellow. The high internal reflectivity of the thickened sclera, together with the preservation of the image of the sclera when the beam is attenuated, are highly suggestive of scleritis. ${ }^{21.23}$ Modern ocular ultrasound equipment has a calliper function which can be used to measure thickened sclera and compare it with the sclera of the fellow eye. We feel values of scleral thickness greater than $1.8 \mathrm{~mm}$ are very suggestive of scleritis. A-scan ultrasonography will also demonstrate scleral thickening and if a printout of the pre-operative biometry scan is available this also forms a useful basis for comparison.

In healthy patients who had completely uncomplicated operations, and who went on to develop diffuse scleritis, we have found no association with any pre-operative ocular or systemic disease or any intra-operative complication. We were able to demonstrate a statistically significant association with general anaesthesia in our patients, but the cause of this is obscure. Local anaesthesia was our preferred method, but general anaesthesia was selected at patient preference, or if the case was anticipated to be complicated or difficult (e.g. previous surgery or patient apprehension especially in a younger person. We cannot explain the association of SIDS with general anaesthesia. It may be an age-related effect, as the patients who developed scleritis following surgery under general anaesthetic were significantly younger than those who underwent surgery with local anaesthetic (Student's $t$-test, $p=0.004$ ). Tuft and Watson ${ }^{22}$ have shown anterior diffuse scleritis to present in younger patients than other forms of scleritis. We were unable to demonstrate an association between scleritis following general anaesthesia with any other preor per-operative factor.

Necrotising scleritis is well recognised as a rare sequela following surgery. In 1979, Lyne and Lloyd Jones' described 6 cases of necrotising scleritis, 3 of which followed cataract surgery, in 1980 Bloomfield et al. ${ }^{2}$ reported 1 case of necrotising scleritis with corneal ulceration following intracapsular cataract extraction; and more recently, Salacz ${ }^{7}$ has also reported 1 case. O'Donoghue et $a l .{ }^{10}$ reported 52 eyes which developed surgically induced necrotising scleritis (SINS) adjacent to a surgical wound. In their series of post-surgical scleritis, $96 \%$ developed the necrotising form of the disease, while $23 \%$ also developed secondary posterior scleritis. A variety of surgical procedures were implicated, although most were related to cataract surgery. None of their cases were reported as diffuse scleritis.

While scleritis is thought to be a Gel and Coombs type III immune complex reaction, ${ }^{24.25}$ with deposition of immune complexes, affecting scleral blood vessels, ${ }^{6.25}$ the aetiology of post-surgical necrotising scleritis is not certain. It has been associated with surgery, ${ }^{25}$ multiple surgical events, ${ }^{1.10}$ predisposed patients ${ }^{6}$ and infection. ${ }^{10.13}$ Fong et al. ${ }^{25}$ described the immunohistopathological findings of a series of 25 necrotising scleritis patients, of whom 6 were post-surgical, and 5 chronic non-necrotising scleritis patients, in which neutrophil infiltration and immune complex deposition with fibrinoid necrosis, consistent with type III immune complex reaction, were found. Sainz-de-la-Maza and Foster ${ }^{6}$ also described the immunopathological findings of neutrophil infiltration and immune complex deposition in vascular walls postoperatively in predisposed patients. In addition, both Fong et al. and Sainz-de-la-Maza and Foster described increased HLA-DR expression and the presence of helper T-lymphocytes. This suggests a T-cell immune response 
may be involved following the activation, by surgical trauma, of scleral fibroblasts to show HLA-DR expression and thereby to act as antigen-presenting cells. ${ }^{6.25}$ The role of these factors in SIDS is not certain, although interleukin- $1 \beta$ has been shown to be raised in diffuse scleritis, ${ }^{26}$ and mediators of inflammation (e.g. complement $\mathrm{Cl}$ and Langerhans cells) are present in sclera and peripheral cornea. $^{27,28}$

We were not able to demonstrate an association with a previous history of ocular surgery, nor with a specific procedure or intra-operative manipulation such as posterior capsular damage and vitreous loss or iris surgery. Cataract surgery per se, and the role of circulating antibodies to lens protein, have little supporting evidence: Patel et al. ${ }^{29}$ found no scleritic patient with anti-lens antibodies. Infection may be implicated, ${ }^{6,13,30}$ but not a prerequisite - only 1 of our patients developed a sticky eye.

Scleritis is well recognised in association with rheumatoid disease (for which it has a sinister prognosis), collagen vascular disorders and autoimmune diseases. ${ }^{21}$ Only 1 of our patients suffered from rheumatoid disease. In a retrospective study, Jones and Maguire ${ }^{31}$ found no cases of scleritis in rheumatoid patients who had undergone cataract surgery. Scleritis has been reported in a rheumatoid patient who had undergone intracapsular cataract extraction with transscleral fixation of an anterior chamber intraocular lens implant. ${ }^{9}$ Haider $^{8}$ reports 1 case of scleritis in which the intraocular lens was extruded in a patient with ankylosing spondylitis. None of our patients was identified as suffering from any other predisposing systemic condition.

Surgically induced necrotising scleritis may develop months after surgery: Lyne and Lloyd-Jones ${ }^{1}$ found 9-12 months, and O'Donoghue 40 months, ${ }^{10}$ but Sainz-de-laMaza and Foster ${ }^{6}$ found a range from 2 weeks to 6 months. Fong et al. ${ }^{21}$ cite the post-surgical patients in their group to have presented between 1 and 6 months post-operatively. Our patients developed their symptoms and signs much earlier in the early post-operative phase: 19 of 21 in the first fortnight.

Treatment is aimed at relief of pain and control of inflammation. Local steroid treatment is ineffective. ${ }^{10}$ All, bar one, of our patients with SIDS responded well to oral non-steroidal anti-inflammatory drugs. In contrast, O'Donoghue et al. ${ }^{10}$ found systemic corticosteroids and cytotoxics to be necessary to control SINS, and cyclospo$\operatorname{rin}^{32.33}$ or intravenous pulsed methylprednisolone ${ }^{34}$ have been advocated by other authors. A poor prognosis and even removal of the eye has been found necessary in some cases of SINS: Behrendt and Eckardt ${ }^{5}$ reported 2 cases in which the eyes were lost despite intensive systemic treatment.

Other therapeutic options have been proposed. Hakin et $a l .{ }^{35}$ (although not treating post-operative patients specifically) found orbital floor steroid injections to be of value in necrotising scleritis, but of limited use in uniocular nonnecrotising scleritis.

We found the mean age of our series of patients with
SIDS to be significantly lower than the mean for all cataract patients. In a review of the progression of scleritis, Tuft and Watson ${ }^{22}$ found anterior diffuse scleritis to be the least severe form of the disease; to present in patients of lower age (mean 45.8 years) than other forms of scleritis; and to have a better prognosis with lower overall incidence of visual loss $(9 \%)$ than necrotising disease $(74 \%)$. They also showed the posterior form of the disease to carry most threat to vision. In our series of patients with SIDS, there were only 3 with vision worse than $6 / 18$ Snellen, of which 1 was aphakic.

We wish to bring to the attention of ophthalmologists that surgically induced diffuse scleritis (SIDS) develops in the early post-operative period following cataract surgery; and that, after astigmatism, it is one of the most common complications requiring intervention. We cannot identify the cause of SIDS, but it has a tendency to occur in younger patients and in those undergoing general anaesthetic. We believe SIDS should be included in the differential diagnosis of the post-operative painful red eye, and that B-scan ultrasonography should be performed routinely then to examine scleral thickness. Recognition of this condition allows prompt treatment with non-steroidal anti-inflammatory drugs (our currently favoured drug is flurbiprofen $100 \mathrm{mg}$ three times daily), and resolution with good visual result.

We wish to thank Mrs Esther Morris and Mrs Pat Osborne for their assistance in retrieving the case records for this review.

Key words: Cataract surgery, Diffuse scleritis, Post-operative complications.

\section{REFERENCES}

1. Lyne A, Lloyd-Jones D. Necrotizing scleritis after ocular surgery. Trans Ophthalmol Soc UK 1979;99:146-9.

2. Bloomfield SE, Becker CG, Christian CL, Nauheim JS. Bilateral necrotising scleritis with marginal corneal ulceration after cataract surgery in a patient with vasculitis. $\mathrm{Br} \mathbf{J}$ Ophthalmol 1980;64:170-4.

3. Salamon SM, Mondino BJ, Zaidman GW. Peripheral corneal ulcers, conjunctival ulcers, and scleritis after cataract surgery. Am J Ophthalmol 1982;93:334-7.

4. Gregersen E, Jorgensen JS. Necrotising sclerokeratitis following cataract extraction [in German]. Klin Monatsbl Augenheilkd 1988;193:642-4.

5. Behrendt S, Eckardt C. Postoperative necrotising sclerokeratitis [in German]. Klin Monatsbl Augenheilkd 1990;197: $503-5$.

6. Sainz-de-la-Maza M, Foster CS. Necrotising scleritis after ocular surgery: a clinicopathologic study. Ophthalmology 1991;98:1720-6.

7. Salacz G. Postoperative necrotising sclerokeratitis. Doc Ophthalmol 1992;80:167-70.

8. Haider S. Spontaneous extrusion of an intraocular lens implant. J Cataract Refract Surg 1992;18:529-30.

9. Glasser DB, Bellor J. Necrotising scleritis of scleral flaps after transscleral suture fixation of an intraocular lens. Am J Ophthalmol 1992;113:529-32.

10. O’Donoghue E, Lightman S, Tuft S, Watson P. Surgically induced necrotising sclerokeratitis (SINS): precipitating factors and response to treatment. Br J Ophthalmol 1992;76: $17-21$.

11. Lyons CJ, Dart JK, Aclimandos WA, Lightman S, Buckley RJ. Sclerokeratitis after keratoplasty in atopy. Ophthalmology 1990;97:729-33. 
12. Kaufman LM, Folk ER, Miller MT, Tessler HH. Necrotising scleritis following strabismus surgery for thyroid ophthalmology. J Pediatr Ophthalmol Strabismus 1989;26:236-8.

13. Carlson AN, Foulks GN, Perfect JR, Kim JH. Fungal scleritis after cataract surgery: successful outcome using itraconazole. Cornea 1992;11:151-4.

14. Ansons AM, Benson C, Clearkin LG. Scleritis following intraocular lens implantation. Eur J Implant Refract Surg 1991:3:261-5.

15. Watson PG, Hayreh SS. Scleritis and episcleritis. Br J Ophthalmol 1976;60:163-91.

16. Watson PG. The diagnosis and management of scleritis. Ophthalmology 1980;87:716-20.

17. Wilhelmus KR, Grierson I, Watson PG. Histopathologic and clinical associations of scleritis and glaucoma. Am J Ophthalmol 1981;91:697-705.

18. Courtney P. The National Cataract Surgery Survey. I. Method and descriptive features. Eye 1992;6:487-92.

19. Desai P. The National Cataract Surgery Survey. II. Clinical outcomes. Eye 1993;7:489-94.

20. Quinlan MP, Hitchings RA. Angle-closure glaucoma secondary to posterior scleritis. Br J Ophthalmol 1978;62:330-5.

21. Benson WE. Posterior scleritis. Surv Ophthalmol 1988:32: 297-316.

22. Tuft SJ, Watson P. Progression of scleral disease. Ophthalmology 1991;98:467-71.

23. Cappaert WE, Purnell EW, Frank KE. Use of B-sector scan ultrasound in the diagnosis of benign choroidal folds. Am J Ophthalmol 1977;84:375-9.

24. Gel PGH, Coombs RRA. Clinical aspects on immunology. Oxford: Blackwell Scientific, 1968.
25. Fong LP, Sainz-de-la-Maza M, Rice BA, Kupferman AE, Foster CS. Immunopathology of scleritis. Ophthalmology 1991;98:472-9.

26. Palexas GN, Puren A, Savage N, Welsh NH. Serum interleukin (IL-1 beta) in patients with diffuse scleritis. Scand J Immunol 1992;36:171-2.

27. Mondino BJ. Inflammatory diseases of the peripheral cornea. Ophthalmology 1988;95:463-72.

28. Brawman-Mintzer O, Mondino BJ, Mayer FJ. The complement system in sclera. Invest Ophthalmol Vis Sci 1988;29: 1756-8.

29. Patel M, Shine B, Murray PI. Antilens antibodies in cataract and inflammatory eye disease: an evaluation of a new technique. Int Ophthalmol 1990;14:97-100.

30. Mannis MJ, Tamaru R, Roth AM, Burns M, Thirkill C. Acanthamoeba sclerokeratitis: determining diagnostic criteria. Arch Ophthalmol 1986;104:1313-7.

31. Jones RR, Maguire LJ. Corneal complications after cataract surgery in patients with rheumatoid arthritis. Cornea 1992; $11: 148-50$

32. Wakefield D, McCluskey P. Current concepts in the management of scleritis. Aust NZ J Ophthalmol 1988;16:169-76.

33. Hakin KN, Ham J, Lightman SL. Use of cyclosporin in the management of steroid-dependent non-necrotising scleritis. Br J Ophthalmol 1991:75:340-1.

34. McCluskey P, Wakefield D. Intravenous pulse methylprednisolone in scleritis. Arch Ophthalmol 1987;105:793-7.

35. Hakin KN, Ham J, Lightman SL. Use of orbital floor steroids in the management of patients with uniocular nonnecrotising scleritis. Br J Ophthalmol 1991;75:337-9. 